\title{
The effect of life skills training on the educational stress deduction of the Islamic Azad University students in 2013-2014
}

\author{
${ }^{1}$ Rostami, Mehdi ${ }^{2}$ Karimi, Qumarth \\ ${ }^{1}$ Department of Psychology, Sanandaj Branch, Islamic Azad University, Sanandaj, Iran \\ ${ }^{2}$ Department of Psychology, Mahabad Branch, Islamic Azad University, Mahabad, Iran \\ E-mail address: mm.rostami1355@gmail.com
}

\begin{abstract}
Keywords: educational stress; life skills training
\end{abstract}
\begin{abstract}
This article aims to determine the level of life skills training effect on the educational stress of the Islamic Azad University students of Sanandaj in 2013-2014 and it was done by using the experimental research method with pre-test and post-test of interviewed (testifier) group. The statistic society of this article consist of all Islamic Azad University students of Sanandaj in 2013 2014 that based on statistics it was about 11000 persons that Cochran's model was used for estimating the sample size and 277 persons were chosen casually. According to the sample size, firstly the student life stress questionnaire was performed and 60 persons of people that had maximum students life stress depend on questionnaire scale were chosen and screened. The 60 screened persons were divided into two experimental group and control group. It means that 30 people in the experimental group that was taken under the life skills training and 30 people as Control group in order to being compared with the experimental group in the terms of life skills training effect of the educational stress. For surveying the variable $\mathrm{s}$ relation, analysis statics and independent $\mathrm{T}$ test were used. The result showed that in the terms of life skills training effect on educational stress (there is a meaningful difference between the experimental group and control group) or in other hand, life skills had meaningful effect on the educational stress deduction.
\end{abstract}

\section{INTRODUCTION}

The stressful situation may occur (happen) to anyone and students aren't exception but they are subjected by more stressful factors (Carlson LE, 2005). Costs payment, working while studying, mind occupation (pre occupation) for containing education, taking courses, doing assignment, continuous evaluations, the need of constant readiness and complying the family expectation in the terms of education success are stressful factors that students are forced with. Moreover, living in dormitory, taking a long with each other, new life style and sleeping and awakening times are disorient factors that affect most of the dormitory students (Haji Bagheri, 2006).

Although a normal degree of stress can increase the student's creativity and success but exorbitance pressure provide a resource of mental or psychological pressure for students and hurt their health in the way that challenges affect their learning ability (farhang, 2008) According to this, many universities recently have come to train the life skills and skills to encounter the mental pressure (stress) for improving their student's health(Otoufi, 2006).

In recent years, many changes have occurred in people life, culture, economic and technical environments changes are encountered the human of current era with different problems. These basic and discrete changes have effected mental health that is one of the most important needs of today's people, people physically and virtually needs to learn ability and skills for communicating with others, facing with life tensions (stresses) with their own special methods. Solving critical matters (issue) personally and ability to using technology which is permanently evolved, problem solving skills, Etc. For this sake person should know him/her-self, having self-knowledge on their excitements and being able to control of guide it in positive way, knowing others and being able to have an effecting relation and even though not unable to accepting different information but assist 
them, so they need an ability to use knowledge (science) in effective way. These kinds of skills are called life skills. In fact life skills are a collection of abilities that provide a useful positive and correspondence field (Taromian 2008).

This skill makes person able to take responsibility of his/her personal and social role and without hurting him/her-self and others respond to him/her needs, expectations and daily issues effectively. World Health Organization calls life skills: ability to acting correspondingly and positively in a way that person could take along with the life challenges and necessities.

Vigenbakh, Gary and James (1991) quotes from Adib (2003) life skills are skills that will be used for improving communication level, increasing decision making ability, communicating with others, learning self-understanding and co-operating in group. UNICEF (2003) says that life skills are called large group of psychological, social and interpersonal skills which can help people to make decision with awareness, making relation effectively, and developing their coping skills, selfmanagements skills and having healthy life (same resource). Accordingly to the mentioned data this research aims to answer to this question that teaching life skill how much effect on reducing educational stress of Islamic Azad University students of Sanandaj?

\section{THEORETICAL BASIS}

\section{1.stress}

In current century "Stress" is one of the most important fields of research in different sciences, this subject received attention of scientist in different majors such as doctors, psychologist, biologist, sociologist and each of them have examined some aspects of stress and complications. In recent decades this specialists co-operation leads to shaping up fields like "Health psychology", "behavioral medicine", psychosomatic" which they have paying to the effect of stress on behavior, psychological health and mental disorders. Nowadays because of stressful factors expansion and human facing ability deduction against them, life style changing, stress has become a big and complicated phenomenon it has taken effect from different factors and the cooperation among them. One of the most important phenomenon that leads to stress can be migration to the larger cities and abroad, industrialization, moreover evolution and tech and science (development) speed, population increase, denying past customs, family relationship changes, the changing role of family disruption, war and expanded stress about nuclear war, poverty, disabilities, chronic disease and changing in cultural and social values (Freedenberg and Louis, 1993). It's obvious that stress is an inseparable part of human life so it's necessary for anyone to know and have knowledge about the way of facing with (these stresses), with learning about its production factors we can produce a background to encounter with them. Various forms of social support produce a background to reduce and inhabitation the emotional and psychological problems. The severity of stressful event, its kind, person's characteristic properties, age and personal experience are most important variables can affect the choice of method.

The events like death of a loved person, flood, earthquake, chronic diseases and divorce are kind of event can lead to stress (tension) in the most of people. The effect level of some events on the physical and emotional dimension of person can be different in a special period. For example, it seems that parents death in childhood have more effects on the person mental health than the other periods. Also the stress of confliction with parents increases in the adolescence. Reacting to stress can have an important role in personal correspondence; persons differ in the assessment of stressful event with each other. They find a compromise to stress and reduce it with different types. Characteristic features are effective in assessment and in a result, individual adaption to stress, so that when two people in front a certain events may they react totally differently. Occurrence of an event can cause a severe anxiety, depression or other physical and psychological diseases in the individual, while this event may have less negative impact on other person or make a slight change in his behavior. Organism (person) for being adapted with stressful events should try to use more than his/her personal capacity represent desirable answers (physiologic, psychological and behavioral).people tolerance in front of stressful events are different which shows people adaption toward environment. Some people have high threshold (residence capacity) and receive less damage 
from stress. Cognitive reactions, emotional, behavioral and physical are kinds of actions which people in fronting with stress will show.

\section{2. life skills}

Different definition for the life skills from World Health Organization (WHO) and UNICEF are represented. World Health Organization, calls life skills as ability that help the individual to be adapted with challenges and necessities of life by expressing adaptive and positive behavior. UNICEF definition of life skills, suggests change or shape the behavior which lead to a balance between three areas of science, attitude and life skills; this definition is based on research evidence that shows if science, attitude, life skills don't be considered simultaneously in empowerment of individual, we can't reduce high-risk behaviors. Accordingly to the UNICEF definition, life skills can be categorized into three stages.

First stage: basic social and psychological skills. These stage skills are affected by culture and values like self-consciousness and pity.

Second stage: special skills, this stage skills will be used only in special situation like negotiation to rectify a conflict and recklessly (bravely) acting.

Third stage: applied skills, like refusing drugs or fighting with gender and traditional rules. Elsewhere, clearly emphasizes the important of " spiritual strength and resiliency " and it encourages educators and their audiences well to try to strengthen individual and social life skills with a variety of methods and teachings.

World Health Organization categorized basic skills into three classes or groups, too:

1- Skills related to critical thinking and decision making. These skills included how to obtain information, analysing them and the ability to assess the impact of each of these information on person actions and others.

2- Interpersonal and communicational skills. These skills are related to verbal and non-verbal communication, active listening and ability to expressing fillings and giving feedback, negotiation skills, recklessly acting skill, pity and collaboration are in this category.as a result, this group has contributed to social acceptance and healthy social behaviour.

3- Coping skills and self-management. These skills are very effective in strengthening internal control and the learners' individual how to influence those around him. Self-esteem, self awareness (consciousness), self-evaluation skills and time management are also part of selfmanagement skills.

\section{RESEARCH METHODOLOGY, STATISTICAL POPULATION AND SAMPLE}

These research aimed to measure amount of educational stress reduce in Azad university of Sanandaj students in (2013-2014) by teaching life skills to them with using pre-test - post-test model experimental research method which is done with control group. The statistical population of this study included all Azad university of Sanandaj students in (2013-2014) which is estimated nearly 11000 by Cochran's model and 277 of students chosen randomly. According to the statistical population mass first SLSI questionnaire applied and about 60 students how most stress (tension) had were screened and selected. Those sixty people whom screened randomly divided into the Test group and Control Group. This means 30 people in test group which were taught life skills and those other 30 people known as Control group were taken to be compared with Test group for studying amount of teaching life skills effects on educational stress.

\section{DATA (FINDINGS)}

Assumption: Teaching life skills cause educational stress reduce for studying (Test group and Control group) difference between studied groups The $\mathrm{T}$ test have been used according to the data inserted in table 1, educational stress comparison of studied groups as follows: 
Table (1): Educational stress comparison of studied groups

\begin{tabular}{|c|c|c|c|c|c|c|c|c|}
\hline $\begin{array}{c}\text { Grouping } \\
\text { variable }\end{array}$ & levels & amplitude & average & $\begin{array}{c}\text { Standard } \\
\text { deviation }\end{array}$ & $\begin{array}{c}\text { Standard } \\
\text { error }\end{array}$ & T Statics & $\begin{array}{c}\text { Degrees } \\
\text { of } \\
\text { freedom }\end{array}$ & $\begin{array}{c}\text { Significant } \\
\text { level }\end{array}$ \\
\hline $\begin{array}{c}\text { educational } \\
\text { stress }\end{array}$ & $\begin{array}{c}\text { Test } \\
\text { group }\end{array}$ & 42 & -31.50 & 22.71 & 3.50 & -11.443 & 65487 & 0.000 \\
\cline { 2 - 8 } & $\begin{array}{c}\text { Control } \\
\text { group }\end{array}$ & 60 & 14.28 & 14.95 & 1.93 & & & \\
\hline
\end{tabular}

Table (1) comparison between educational stress numbers of Test and Control Groups. The result indicate significant difference between two group (Test group and Control group) can be seen which $\mathrm{T}$ amount that has been computed (-11.433) and degree of freedom are more than significant level and amount of significant is less than $\% 0.01$ level so with $\% 99$ n confident we can say that assumption (Teaching life skills will reduces educational stress of students confirmed.

\section{DISCUSSION AND CONCLUSION}

For studying educational stress differences between two studied group (Test group and Control group) $\mathrm{T}$ test have been used. The result indicate significant difference between two group (Test group and Control group) can be seen which $\mathrm{T}$ amount that has been computed (-11.433) and degree of freedom are more than significant level and amount of significant is less than $\% 0.01$ level so with $\% 99$ n confident we can say that assumption (Teaching life skills will reduces educational stress of students confirmed and these differences caused by using and teaching life skills course to Test group. Results of this hypothetical research have overlap with Llopis and co-workers (2005), Magnani and co-workers (2005), Moghadam and co-workers (2008) researches. In specifying data's gathered for this assumption we can say that results of this research shows the logical effects of teaching life skills on educational stress, means, although; in many of theoretical perspectives there is an emphasis on the stresses of adolescence, researchers in social sciences and anthropology have concluded that mainly young people's problems affected by social and cultural conditions because their growth and development, especially in social and emotional background are affected by society developments and changes. Accordingly, methods which adults and youth use to deal with their concerns are widely affected by society. When youth can't effectively deal with their concerns, their behaviour not only can have negative impact on their lives but also it can have more detrimental effects on the family or the larger community who they are subject to it. Methods which youth use to deal with their concerns it may just be the general pattern for their life and also how they plan for the future totally affected by the society they live. Their adaptive behaviour will determine that what will happen in future for them. School and university as a great representative of their sociality can take great part in their health, satisfaction and gratification. Trainer by understanding youth needs and also responding to those needs can help them in dealing with their concerns. This work can be done through social protection programs and educational programs. Teaching dealing methods can be tailored to meet their mental health and teachers and professors (masters) are advised to attend to students style of thinking and their cognitive evaluates regarding to students' academic performance. If youth trained to relate their own academic failure as a controllable factor (the amount of efforts) in that case, maybe they can prevent consequences of failure at that. By Seligman opinion stress like losing parents are effective in how the individual interprets subsequently events and as result predisposition to depression and anxiety. Also Louison, rad, Saily (1994) believe that lack the ability to solve problems and skills to deal properly with various stresses can be considered as appropriate and important factors of vulnerability for attempting to suicide in some youth. So education officials have to teach problem solving skills and ways of dealing with stress, and they should help young people to end away from stressful situations, so according these features can be good, because the logical conclusion of the study. 


\section{References}

[1] Adib N,.Designing optimal Planning life skills for School. Unpublished doctoral dissertation. Tarbyat Modares University: Humanities Collage(2003).

[2] Carlson LE. Bultz BD. Morris DG. Individual quality of life, standardized quality of life and distress in patients undergoing a phase I trial of novel therapeutic Reolysin 9reovirus). Health and Quality of Life Outcomes (2005).

[3] Dehqan Niry, Nahid and Adib Hajabaqeri, Mohsen ,. A Study entitled the effect of relaxation on stress and students life quality in student dormitory. Feyz Scientific Journal(2005).

[4] Fatey and Atoufi (2006). Problem solving skill. Tehran. Danzhh publication.

[5] Taromyan, Farhad,. Life skills definitions and basis, the depth of training magazine first year fourth number quoted from specialized Koranic interdisciplinary research journal first year, first number10(2)(2008).

[6] World Health Organization (WHO),. "The skills education project. Geneva". WHO Technical reportseries(1994).

[7] World Organization and life skills program,. Robabeh Noori Qasem Abadi and Parvane Mohammad Khani, Department of health and drug abuse prevention(1998). 